Original Research Article

\title{
Profile of multi drug resistant (MDR) and rifampicin resistant TB patients treated under category IV of RNTCP
}

\author{
Pravin Uike $^{1 *}$, Prabhakar Hiwarkar ${ }^{2}$, Vilas Malkar ${ }^{2}$, Ketan Aswalle $^{2}$
}

\author{
${ }^{1}$ Department of Pharmacology, \\ ${ }^{2}$ Department of Community \\ Medicine, SVN Govt. Medical \\ College, Yavatmal, \\ Maharashtra, India
}

Received: 07 February 2017

Accepted: 06 March 2017

*Correspondence to:

Dr. Pravin Uike,

Email:

pravin_vike@yahoo.co.in

Copyright: (C) the author(s), publisher and licensee Medip Academy. This is an openaccess article distributed under the terms of the Creative Commons Attribution NonCommercial License, which permits unrestricted noncommercial use, distribution, and reproduction in any medium, provided the original work is properly cited.

\begin{abstract}
Background: The emergence of resistance to drugs used to treat tuberculosis (TB) and particularly multidrug resistance TB (MDR-TB) has become a significant health problem and obstacle to effective TB control in India. Present study was conducted to study clinical and sociodemograohic profile of MDR and rifampicin resistant TB patients registered for treatment under RNTCP in Yavatmal district of Maharashtra state.

Methods: All drug resistant (MDR and rifampicin resistant) TB patients residents of Yavatmal district, treated at DOTS plus site with Standardized Treatment Regimen (STR) from 1st quarter 2009 to $3^{\text {rd }}$ quarter 2013 were included. Data was obtained from electronic treatment register maintained at DOTS Plus site.

Results: There were total 60 confirmed MDR and rifampicin resistant TB patients from Yavatmal district. Male patients $(65.00 \%)$ were comparatively more than females $(35.00 \%)$. Almost half $(46.67 \%)$ of the patients belonged to the productive age group i.e. 30-45 years followed by another one third $(35.00 \%)$ in the age group of $15-30$ years. $93.33 \%$ patients were previously treated under RNTCP (under CAT II), out of them $48.51 \%$ were failure, $37.50 \%$ relapse and $14.29 \%$ defaulter.

Conclusions: Among MDR and rifampicin resistant TB patients, maximum patients were males, belonged to the social and productive age group, HIV negative and previously treated due to treatment failure.
\end{abstract}

Keywords: MDR-TB, Rifampicin resistant, RNTCP Category IV, STR

\section{INTRODUCTION}

The emergence of resistance to drugs used to treat tuberculosis (TB) and particularly multidrug resistance TB (MDR-TB) has become a significant health problem and obstacle to effective TB control in India ${ }^{1}$. MDR-TB is defined as resistance to isoniazid and rifampicin with or without resistance to other drugs. ${ }^{1}$

Prevalence of MDR TB in India is less than 1-3\% and around $12-17 \%$ among the new and retreatment cases respectively. ${ }^{2,3}$ Under revised national tuberculosis control program (RNTCP) both MDR and rifampicin resistant TB patients are suspected from Category I and II patients and diagnosed by sputum culture. They are included under category IV and treated with Standardized Treatment Regimen (STR).

Present study was conducted to study clinical and sociodemograohic profile of MDR and rifampicin resistant TB patients registered for treatment under RNTCP in Yavatmal district of Maharashtra state.

\section{METHODS}

Observational type of descriptive study was conducted at DOTS plus site at Akola (which caters five districts including Yavatmal) Maharashtra. All drug resistant (MDR and rifampicin resistant) TB patients treated with Standardized Treatment Regimen (STR) from $1^{\text {st }}$ quarter 2009 to $3^{\text {rd }}$ quarter 2013 were included. Data was 
obtained from electronic treatment register maintained at DOTS Plus site. Data was analyzed with SPSS and epiinfo software. Permission from institutional ethical committee was obtained before beginning of the study. Privacy and confidentiality of the data was strictly maintained.

Drug resistant suspects can be any of the following:

1. RNTCP category I and II failure patients. ${ }^{1}$

2. RNTCP category II sputum smears positive TB patients at the end of four months or later.

3. Sputum smears positive close contacts of confirmed drug resistant TB patients.

Drug resistant suspects are confirmed by culture and sensitivity of their sputum samples. Line Probe Assay (LPA) method is used for culture of sputum and proportion method is used for drug sensitivity testing.

Confirmed patients of drug resistant TB are put in category IV under RNTCP and treated with standardized treatment regimen (STR) after pretreatment evaluation. STR compromises intensive phase of six months (extended upto nine months depending upon follow up sputum culture result) and continuation phase of eighteen months. Intensive phase consists of daily administration six drugs namely Kanamycin, Ofloxacin, Ethionamide, Cycloserine, Pyrazinamide and Ethambutol. Similarly continuation phase consists of daily administration four drugs namely Ofloxacin, Ethionamide, Cycloserine and Ethambutol.

\section{RESULTS}

There were total 60 confirmed MDR and rifampicin resistant TB patients from Yavatmal district were registered for category IV treatment under RNTCP and administered Standard Treatment Regimen (STR) for it.

Table 1: Type of drug resistance.

\begin{tabular}{|lll|}
\hline & No & $\%$ \\
\hline Rifampicin Resistance & 18 & 30.00 \\
\hline Multidrug Resistance (MDR) & 42 & 70.00 \\
\hline
\end{tabular}

Out of those 60 patients treated $70.00 \%$ patients had MDR TB (resistant to both isoniazid and rifampicin) and remaining $30.0 \%$ were resistant to rifampicin and sensitive to isoniazid.

Table 2: Year wise distribution of patients.

\begin{tabular}{|lll|}
\hline Year & No & $\%$ \\
\hline 2009 & 09 & 15.00 \\
\hline 2010 & 12 & 20.00 \\
\hline 2011 & 17 & 28.33 \\
\hline 2012 & 22 & 36.67 \\
\hline
\end{tabular}

There was gradual increase in number of patients treated from year 2009 (09) to year 2012 (22).

Table 3: Demographic profile of drug resistant TB patients.

\begin{tabular}{|c|c|c|}
\hline & No & $\%$ \\
\hline \multicolumn{3}{|c|}{ Gender wise distribution of patients } \\
\hline Male & 39 & 65.00 \\
\hline Female & 21 & 35.00 \\
\hline \multicolumn{3}{|c|}{ Age group wise distribution of patients } \\
\hline$<15$ years & 00 & 00.00 \\
\hline $15-30$ years & 21 & 35.00 \\
\hline $30-45$ years & 28 & 46.67 \\
\hline $45-60$ years & 10 & 16.67 \\
\hline$>60$ years & 01 & 1.66 \\
\hline \multicolumn{3}{|c|}{ Residence wise distribution of patients } \\
\hline Urban & 17 & 28.33 \\
\hline Rural & 43 & 71.67 \\
\hline
\end{tabular}

Male patients $(65.00 \%)$ were comparatively more than females $(35.00 \%)$. Almost half $(46.67 \%)$ of the patients belonged to the productive age group i.e. 30-45 years followed by another one third $(35.00 \%)$ in the age group of 15-30 years.

Age of the patients ranged from 15-62 years with mean 36.94 years and standard deviation 12.69years.Patients from the rural area $(\%)$ outnumbered those from urban area $(\%)$.

Table 4: HIV status of patients.

\begin{tabular}{|lll|}
\hline & No & $\%$ \\
\hline HIV Positive & 03 & 05.00 \\
\hline HIV Negative & 57 & 95.00 \\
\hline
\end{tabular}

Very few (only 3 out of 60 i.e. $05.00 \%$ ) patients were HIV positive and rest $95.00 \%$ were HIV negative.

\section{Table 5: Previous RNTCP treatment category of patients.}

\begin{tabular}{|c|c|c|}
\hline & No & $\%$ \\
\hline \multicolumn{3}{|c|}{ Previous RNTCP Treatment Category $(n=60)$} \\
\hline Category I (New) & 04 & 6.67 \\
\hline Category II (Previously Treated) & 56 & 93.33 \\
\hline \multicolumn{3}{|c|}{ Previous RNTCP Treatment Outcome $(\mathrm{n}=56)$} \\
\hline Failure & 27 & 48.21 \\
\hline Relapse & 21 & 37.50 \\
\hline Defaulter & 08 & 14.29 \\
\hline
\end{tabular}

93.33\% patients were previously treated under RNTCP (under CAT II); out of them $48.51 \%$ were failure, $37.50 \%$ relapse and $14.29 \%$ defaulter. Rest $6.67 \%$ patients were new (RNTCP category I). 


\section{DISCUSSION}

As per the guidelines of RNTCP, both MDR (resistant to both and rifampicin resistant, TB patients are included under category IV and given STR after pre-treatment evaluation. Total such confirmed resistant TB patients from Yavatmal district were registered and treated at DOTS plus site Akola.

Out of those 60 patients treated, 42 (70.00\%) had MDR TB (resistant to both isoniazid and rifampicin) and remaining $18(30.0 \%)$ were resistant to only rifampicin and not to isoniazid. Similar findings were reported in a study by Kalpesh Jain et al where $93.00 \%$ patients had MDR TB and $7.00 \%$ were resistant to only rifampicin. ${ }^{4}$ They also observed that the pattern of drug resistance was not significantly associated with the outcome of treatment with STR.

Total number of patients registered and treated at DOTS plus site went on gradually increasing from the year 2009, when that DOTS plus site was established, to the year 2013. It may be due to gradual intensifying case finding and case referral activities as well as enhancing capacity of the DOTS plus center. This trend is consistent with that revealed by Joint Monitoring Mission report which shows that in India only 1174 rifampicin resistant patients were put on treatment in the year 2009 which went increasing gradually year by year and in 2012, total 14117 patients were given treatment under category IV under RNTCP. ${ }^{5}$

Demographic profile of these patients showed that male $(65.00 \%)$ patients outnumbered the female $(35.00 \%)$ patients. Similar male dominance was also recorded in the various studies in India as well as Abroad. ${ }^{6-9}$ It may be the reflection of similar proportion of new(CAT-I) TB patients under RNTCP where among all patients treated from 1999 to year 2014, almost three fourth (74\%) were males. ${ }^{5}$

Regarding the age group, except one, all patients were from productive age group i.e. 15-60 years and out of them half of them $(46.67 \%)$ were from the age group of $30-45$ years. Concentration of the patients in this most productive age group gives the idea regarding adverse social and economical consequences for their affected families, communities, states and country as a whole. Consistent findings were well documented in studies in India as well as from Abroad. ${ }^{4,6,8,9,10-12}$ Similar to male dominance, social and economic age group involvement among the drug resistant TB patients is similar to that observed among newly diagnosed TB patients. ${ }^{5}$

Among all 60 resistant TB patients, only 5.00\% were HIV positive and rest $95.00 \%$ were HIV negative. Very less proportion of HIV positive patients among drug resistant TB patients is also recorded by Kapadia VK et al $(1.2 \%)$, Bhatt $\mathrm{G}$ et al $(6.34 \%)$, Ceatano Mota $\mathrm{P}$ et al $(11 \%))^{7,10,13}$ Additionally all of them found no significant statistical association between HIV status of patients and treatment outcome.

Only 4 out of 60 (i.e. $6.67 \%$ ) drug resistant patients were from CAT I. Rest $93.33 \%$ patients were previously being treated under RNTCP (under CAT II) i.e. these patients were first treated under CAT I, but due to either failure or relapse or default, they were being retreated under CAT II. Out of these 56 patients, $48.51 \%$ were included under CAT II due to CAT I treatment failure, $37.50 \%$ due to relapse after successfully completing CAT I treatment and $14.29 \%$ due to defaulting CAT I treatment. Sharma $\mathrm{S}$. K et al in their study reported that among previously treated drug resistant TB patients, maximum (75.00\%) were of relapse followed by $16.8 \%$ defaulter and of failure $(8.2 \%){ }^{6}$ In another study by Bhatt $\mathrm{G}$ et al revealed almost equal proportion of relapse $(30.9 \%)$, defaulter $(28.4 \%)$ and failure $(27.2 \%)$ patients among previously treated drug resistant TB patients. ${ }^{14}$

\section{Funding: No funding sources}

Conflict of interest: None declared

Ethical approval: The study was approved by the Institutional Ethics Committee

\section{REFERENCES}

1. Central TB Division. Guidelines on Programmatic Management of Drug Resistant TB (PMDT) in India. Central TB Division. 2012;124. Available from: http://tbcindia.gov.in/WriteReadData/1892s/8320929 355Guidelines for PMDT in India - May 2012.pdf\%5Cnhttp://www.tbcindia.gov.in/showfile.p hp?lid=3155

2. Mahadev B, Kumar P, Agarwal SP, Chauhan LS, Srikantaramu N. Surveillance of drug resistance to anti-tuberculosis drugs in districts of Hoogli in West Bengal and Mayurbhanj in Orissa. Indian J Tuberc. 2005;52:5-10.

3. Paramasivan $\mathrm{CN}$, Venkataraman $\mathrm{R}$, Chandrasekaran V, Bhat S, Narayanan RR. Surveillance of drug resistance in tuberculosis in two districts of South India. Int J Tuberc Lung Dis. 2002;6(6):479-84.

4. Jain K, Desai M, Solanki R, Dikshit RK. Treatment outcome of standardized regimen in patients with multidrug resistant tuberculosis. J Pharmacol Pharmacother. 2014;5:145-9.

5. World Health Organization, Joint Monitoring Mission for Revised National Tuberculosis Control Programme. SEARO. World Health Organization, South-East Asia Regional Office; 2016.

6. Sharma SK, Kumar S, Saha PK, George N, Arora SK, Gupta D, et al. Prevalence of multidrug-resistant tuberculosis among Category II pulmonary tuberculosis patients. Indian $\mathrm{J}$ Med Res. 2011;133(3):312-5.

7. Kapadia VK, Sanjay T. Analysis of 63 patients of MDR TB on DOTS plus regimen: An LG hospital, TB Unit, Ahmedabad experience. 
8. Teixeira L, Perkins MD, Johnson JL, Keller R, Palaci M, Do Valle Dettoni V, et al. Infection and disease among household contacts of patients with multidrug-resistant tuberculosis. Int J Tuberc Lung Dis. 2001;5(4):321-8.

9. Bayona J, Chavez-Pachas AM, Palacios E, Llaro K, Sapag R, Becerra MC. Contact investigations as a means of detection and timely treatment of persons with infectious multidrug-resistant tuberculosis. Vol. 7, International Journal of Tuberculosis and Lung Disease; 2003:S501-9.

10. Bhatt G, Vyas S, Trivedil K. An epidemiological study of multi drug resistant tuberculosis cases registered under Revised National Tuberculosis Control Programme of Ahmedabad City. Indian $\mathbf{J}$ Tuberc. 2012;59(1):18-27.

11. Joseph P, Desai VBR, Mohan NS, Fredrick JS, Ramachandran R, Raman B, et al. Outcome of standardized treatment for patients with MDR-TB from Tamil Nadu, India. Indian $J$ Med Res. 2011;133(5):529-34.
12. Vella V, Racalbuto V, Guerra R, Marra C, Moll A, Mhlanga $\mathrm{Z}$, et al. Household contact investigation of multidrug-resistant and extensively drug-resistant tuberculosis in a high HIV prevalence setting. Int $\mathbf{J}$ Tuberc Lung Dis. 2011;15(9):1170-5.

13. Caetano Mota P, Carvalho A, Valente I, Braga R, Duarte R. Predictors of delayed sputum smears and culture conversion among a Portuguese population with pulmonary tuberculosis. Rev Port Pneumol 2012;18(2):72-9.

14. Bhatt G, Vyas S, Trivedil K. An epidemiological study of multi drug resistant tuberculosis cases registered under Revised National Tuberculosis Control Programme of Ahmedabad City. Indian J Tuberc. 2012;59(1):18-27.

Cite this article as: Uike P, Hiwarkar P, Malkar V, Aswalle K. Profile of multi drug resistant (MDR) and rifampicin resistant TB patients treated under category IV of RNTCP. Int J Basic Clin Pharmacol 2017;6:784-7. 